\title{
A comprehensive evaluation for aspiration after esophagectomy reduces the incidence of postoperative pneumonia
}

\author{
Mark F. Berry, MD, ${ }^{\mathrm{a}} \mathrm{B}$. Zane Atkins, MD, ${ }^{\mathrm{b}}$ Betty C. Tong, MD, ${ }^{\mathrm{a}}$ David H. Harpole, MD, ${ }^{\mathrm{a}}$ \\ Thomas A. D'Amico, MD, and Mark W. Onaitis, MD ${ }^{\mathrm{a}}$
}

\begin{abstract}
Objective: This study assesses the effect of using a comprehensive swallowing evaluation before starting oral feedings on aspiration detection and pneumonia occurrence after esophagectomy.

Methods: The records of all patients undergoing esophagectomy between January 1996 and June 2009 were reviewed. Multivariable logistic regression analysis assessed the effect of preoperative and operative variables on the incidence of aspiration and pneumonia. Separate analyses were performed on patients before (early era, 1996-2002) and after (later era, 2003-2009) a rigorous swallowing evaluation was used routinely before starting oral feedings.
\end{abstract}

Results: During the study period, 799 patients ( 379 from the early era and 420 from the later era) underwent esophagectomy; 30 -day mortality was $3.5 \%$ (28 patients). Cervical anastomoses were performed in $76 \%$ of patients in the later era compared with $40 \%$ of patients in the early era. Overall, $96(12 \%)$ patients had evidence of aspiration postoperatively, and the pneumonia incidence was 14\% (113 patients). Age (odds ratio, 1.05 per year; $P<.0001$ ) and later era (odds ratio, 1.90; $P=.0001$ ) predicted aspiration in all patients in a multivariable model. In the early era, cervical anastomosis and aspiration independently predicted pneumonia. With a comprehensive swallowing evaluation in the later era, the detected incidence of aspiration increased $(16 \% \mathrm{vs} 7 \%$, $P<.0001)$, whereas the incidence of pneumonia decreased (11\% vs $18 \%, P=.004)$ compared with the early era, such that neither anastomotic location nor aspiration predicted pneumonia in the later era.

Conclusions: Esophagectomy is often associated with occult aspiration. A comprehensive swallowing evaluation for aspiration before initiating oral feedings significantly decreases the occurrence of pneumonia. (J Thorac Cardiovasc Surg 2010;140:1266-71)

Mortality after esophagectomy has improved over time but is still considerable, with perioperative mortality rates in national databases ranging from $8.8 \%$ to $14 \% .{ }^{1-6}$ Esophagectomy is also associated with significant morbidity, as well as relatively long hospital stays and delays to recovery of baseline activity levels. ${ }^{1-5,7-12}$ Although high-volume centers and surgeons have better results than national averages, the effect of surgical complications on survival and quality of life cannot be overstated, especially when considering the poor 5-year survival rate for patients with esophageal cancer. ${ }^{413-15}$ In addition, the morbidity and mortality associated with esophagectomy might be limiting its application in the treatment of esophageal cancer because surgical intervention is used for only $34 \%$ of potentially resectable stage I, II, and III esophageal cancers. ${ }^{16}$

From the Division of Thoracic Surgery, ${ }^{\mathrm{a}}$ Department of Surgery, Duke University Medical Center, Durham, NC; and the Department of Surgery, ${ }^{\mathrm{b}}$ Durham Veterans Affairs Medical Center, Durham, NC.

Disclosures: None.

Read at the 36th Annual Meeting of the Western Thoracic Surgical Association, June 23-26, 2010, Ojai, California.

Received for publication May 24, 2010; revisions received July 23, 2010; accepted for publication Aug 14, 2010; available ahead of print Sept 30, 2010.

Address for reprints: Mark F. Berry, MD, Box 3652, Duke University Medical Center, Durham, NC 27710 (E-mail: berry037@mc.duke.edu).

$0022-5223 / \$ 36.00$

Copyright (c) 2010 by The American Association for Thoracic Surgery doi:10.1016/j.jtcvs.2010.08.038
Respiratory complications are the most common cause of postoperative death after esophagectomy, with postoperative pneumonia having a mortality of $20 \%$. $^{9}$ Pulmonary complications are significant for all techniques used to accomplish esophagectomy, although transhiatal and minimally invasive approaches might have a lower incidence compared with approaches that use a thoracotomy. ${ }^{4,17,18}$ The measures shown to reduce perioperative esophagectomy morbidity (aggressive preoperative conditioning, avoidance of the intensive care unit, improved pain management, use of epidural analgesia, aggressive use of bronchoscopy for clearance of pulmonary secretions, and early ambulation) likely confer benefit by improving the patient's pulmonary toilet and reducing the incidence of pneumonia. ${ }^{8,19}$ Postesophagectomy pneumonia at least partly occurs because of swallowing dysfunction and silent tracheobronchial aspiration, which occur in a significant number of patients undergoing esophagectomy in the early postoperative period. ${ }^{20,21}$

After demonstrating that postesophagectomy pneumonia strongly predicts mortality, ${ }^{9}$ we instituted a routine comprehensive postoperative swallowing evaluation before initiation of oral feedings after esophagectomy, including careful clinical observation, cineradiography, and fiberoptic endoscopy. The purpose of this study was to test the hypothesis that detecting aspiration with this comprehensive swallowing evaluation before initiation of 


\section{Abbreviation and Acronym}

VFSS $=$ videofluoroscopic swallow study

oral feedings after esophagectomy reduces the incidence of pneumonia.

\section{MATERIALS AND METHODS}

After local institutional review board approval was granted, including waiver of the need for patient consent, the Duke University Medical Center Data Center was queried for all Current Procedural Terminology codes linked with esophageal resection between January 1996 and June 2009. Retrospective review of an institutional prospective database maintained on all patients undergoing thoracic surgery documented demographics, significant comorbidities, the use of induction therapy, smoking history, operative indication, intraoperative details, and postoperative course. Chart review was used as necessary to complete data collection.

Any postoperative event prolonging or otherwise altering the postoperative course was recorded along with all operative deaths, which were defined as deaths that occurred within 30 days after the operation or those that occurred later but during the same hospitalization. Deaths were captured both by means of chart review and use of the Social Security Death Index Database. Overall morbidity was defined as the occurrence of at least 1 postoperative event. Aspiration was defined not by clinical suspicion alone but only when confirmed with swallowed contrast observed in the tracheobronchial tree on radiographic studies or swallowed dye or enteric contents observed in the airway on endoscopic studies. Pneumonia was defined as a febrile illness with the presence of a new pulmonary infiltrate or positive sputum culture; ventilator-associated pneumonias were captured in the overall pneumonia rate.
Separate analyses were performed on patients undergoing esophagectomy before (early era, January 1996-December 2002) and after (later era, January 2003-June 2009) a rigorous swallowing evaluation was used routinely before initiation of oral feedings. In the early era, barium swallow was routinely used in the postoperative period to evaluate anastomotic integrity, without concomitant or initial speech/swallow evaluation for aspiration. In the later era, a speech and clinical swallow evaluation was routinely initiated when patients appeared otherwise clinically ready to begin oral feeding, including having adequate respiratory status and appropriate return of bowel function. This evaluation starts with a bedside assessment of oral mechanism, laryngeal elevation during a volitional swallow, and the oral and pharyngeal stages of swallowing with minimal oral feeds with ice and sips of thin liquids, specifically looking for coughing, throat clearing, and changes in voice quality. Patients without overt signs or symptoms of aspiration and patients with overt signs or symptoms of aspiration that could be eliminated with a cup-sip trial and chin-tuck strategy typically then proceed with a videofluoroscopic swallow study (VFSS) combined with a barium swallow study conducted jointly by radiology and the speech pathology service. VFSS allows examination of swallowing function, including inspection of swallow initiation, laryngeal elevation, pharyngeal constriction, laryngeal penetration, tracheal aspiration, and sensory response to penetration or aspiration. Barium swallow is then performed to evaluate anastomotic integrity if aspiration is not observed. Patients who have evidence of aspiration are kept NPO with instructions on oral care and hygiene and started on laryngeal elevation/pharyngeal constriction swallowing exercises, with frequent re-evaluation and reassessment by the speech pathology service. The patient is followed continually by the speech pathology service, with serial re-evaluation conducted radiographically with VFSS or endoscopically with a fiberoptic endoscopic evaluation of swallowing as clinically indicated until the patient's diet can be appropriately advanced.

Unpaired Student's $t$ tests were used to compare continuous data, Fisher's exact tests were used for dichotomous data, and $\chi^{2}$ tests were used for categorical variables. Univariate analyses were performed on all

TABLE 1. Demographics, baseline characteristics, comorbid conditions, and technical operative details of patients undergoing esophagectomy

\begin{tabular}{|c|c|c|c|c|}
\hline Characteristic & All patients $(n=799)$ & Early era $(n=379)$ & Later era $(n=420)$ & $P$ value \\
\hline Age & $61 \pm 11$ & $60 \pm 11$ & $62 \pm 11$ & .03 \\
\hline Tobacco abuse & $497(62 \%)$ & $226(60 \%)$ & $271(65 \%)$ & .17 \\
\hline Pack-years & $42 \pm 26$ & $44 \pm 26$ & $41 \pm 26$ & .29 \\
\hline Induction radiation & $361(45 \%)$ & $167(44 \%)$ & $194(46 \%)$ & .57 \\
\hline Induction chemotherapy & $361(45 \%)$ & $168(44 \%)$ & $193(46 \%)$ & .67 \\
\hline Hypertension & $337(42 \%)$ & $162(43 \%)$ & $175(42 \%)$ & .77 \\
\hline Coronary artery disease & $138(17 \%)$ & $73(19 \%)$ & $65(15 \%)$ & .16 \\
\hline Diabetes & $107(13 \%)$ & $45(12 \%)$ & $62(15 \%)$ & .25 \\
\hline Previous thoracic surgery & $101(13 \%)$ & $34(9 \%)$ & $67(16 \%)$ & .004 \\
\hline Chronic obstructive pulmonary disease & $82(10 \%)$ & $41(11 \%)$ & $41(10 \%)$ & .64 \\
\hline \multicolumn{5}{|l|}{ Indication for esophagectomy } \\
\hline Invasive cancer & $631(79 \%)$ & $305(80 \%)$ & $326(78 \%)$ & .34 \\
\hline Barrett's dysplasia & $85(11 \%)$ & $37(10 \%)$ & $48(11 \%)$ & .42 \\
\hline Other benign condition & $83(10 \%)$ & $37(10 \%)$ & $46(11 \%)$ & .64 \\
\hline \multicolumn{5}{|l|}{ Operative approach } \\
\hline Thoracic and abdominal & $357(45 \%)$ & $195(51 \%)$ & $162(39 \%)$ & $<.0003$ \\
\hline Thoracotomy & $290(36 \%)$ & $195(51 \%)$ & $95(23 \%)$ & $<.0001$ \\
\hline Thoracoscopy & $67(18 \%)$ & 0 & $67(16 \%)$ & $<.0001$ \\
\hline Laparotomy & $351(44 \%)$ & $195(51 \%)$ & $156(37 \%)$ & $<.0001$ \\
\hline Laparoscopy & $6(1 \%)$ & 0 & $6(1 \%)$ & .03 \\
\hline Thoracic (thoracotomy) & $64(8 \%)$ & $41(11 \%)$ & $23(5 \%)$ & .006 \\
\hline Abdominal/transhiatal & $378(47 \%)$ & $143(37 \%)$ & $235(56 \%)$ & $<.0001$ \\
\hline \multicolumn{5}{|l|}{ Anastomosis location } \\
\hline Cervical & $469(59 \%)$ & $150(40 \%)$ & $319(76 \%)$ & $<.0001$ \\
\hline Noncervical & $330(41 \%)$ & $229(60 \%)$ & $101(24 \%)$ & $<.0001$ \\
\hline
\end{tabular}


patients relating aspiration to age, anastomosis location (cervical vs noncervical), use of a thoracotomy in the operative approach, era of operation, history of diabetes, history of tobacco use, coronary artery disease, previous thoracic surgery, and induction therapy. The variables that were significant at $P$ values of .20 or less were entered into a multivariable logistic regression, with aspiration as the dependent variable and significance set at the .05 level. Similar univariate analyses were performed relating pneumonia to aspiration, as well as the above variables, with the analysis repeated separately on the patients by era. The variables that were significant at $P$ values of .20 or less for both eras were entered into a multivariable logistic regression, with pneumonia as the dependent variable and significance set at the .05 level, with analysis again repeated separately on the patients by era. Data are presented as means \pm standard deviations unless otherwise noted. The SAS 9.2 statistical package (SAS Institute, Inc, Cary, NC) was used for statistical analyses.

\section{RESULTS}

During the entire study period, 799 patients (379 from the early era and 420 from the later era) underwent esophagectomy. Baseline demographic characteristics, indications for surgical intervention, comorbid conditions, and operative details are shown in Table 1. Patients in the early and later eras were relatively well matched. The indication for esophagectomy for the majority of patients in both eras was esophageal cancer, with almost half of the patients in each group receiving induction chemoradiation.

A thoracotomy was used in more than $60 \%$ of cases in the early era but only $27 \%$ of cases in the later era. Compared with the early era, minimally invasive approaches with thoracoscopy and laparoscopy were introduced, and a transhiatal approach was used more commonly in the later era. The shift in operative approaches resulted in a different distribution of anastomotic location between the 2 eras, with the anastomosis being performed in the chest in $58 \%$ of patients in the early era but only $22 \%$ in the later era. Conversely, cervical anastomoses were performed in $76 \%$ of patients in the later era compared with $40 \%$ of patients in the early era.

The 30-day operative mortality was $3.5 \%$ (28 patients), with an overall morbidity of $66 \%$ (526 patients) for all of

TABLE 2. Perioperative events after esophagectomy

\begin{tabular}{|c|c|c|c|c|}
\hline Event & All patients $(n=799)$ & Early era $(n=379)$ & Later era $(n=420)$ & $P$ value \\
\hline Thirty-day mortality & $28(3.6 \%)$ & $13(3.4 \%)$ & $15(3.6 \%)$ & .85 \\
\hline Operative mortality & $41(5.1 \%)$ & $21(5.5 \%)$ & $20(4.8 \%)$ & .52 \\
\hline Operative morbidity & $526(66 \%)$ & $241(63 \%)$ & $285(68 \%)$ & .21 \\
\hline Median hospital stay (d) & 10 & 9 & 10 & .3 \\
\hline Arrhythmia & $190(24 \%)$ & $73(19 \%)$ & $117(28 \%)$ & .005 \\
\hline Anastomotic stricture & $177(22 \%)$ & $94(25 \%)$ & $83(20 \%)$ & .09 \\
\hline Anastomotic leak & $117(15 \%)$ & $55(15 \%)$ & $62(15 \%)$ & .92 \\
\hline Pneumonia & $113(14 \%)$ & $68(18 \%)$ & $45(11 \%)$ & .004 \\
\hline Aspiration & $96(12 \%)$ & $27(7 \%)$ & $69(16 \%)$ & $<.0001$ \\
\hline Wound infection & $87(11 \%)$ & $50(13 \%)$ & $37(9 \%)$ & .05 \\
\hline Effusion requiring treatment & $78(10 \%)$ & $33(9 \%)$ & $45(11 \%)$ & .40 \\
\hline Reintubation & $69(9 \%)$ & $20(5 \%)$ & $49(11 \%)$ & .002 \\
\hline Ventilator dependence & $56(7 \%)$ & $29(7.6 \%)$ & $27(6.4 \%)$ & .58 \\
\hline Urinary tract infection & $49(6 \%)$ & $15(4 \%)$ & $34(8 \%)$ & .02 \\
\hline Tracheostomy & $39(5 \%)$ & $16(4 \%)$ & $23(5 \%)$ & .51 \\
\hline Gastric emptying requiring pyloric intervention & $31(4 \%)$ & $1(0.3 \%)$ & $30(7 \%)$ & $<.0001$ \\
\hline Recurrent laryngeal nerve injury & $28(3.5 \%)$ & $7(1.8 \%)$ & $21(5 \%)$ & .02 \\
\hline Deep venous thrombosis/pulmonary embolism & $21(2.6 \%)$ & $9(2.3 \%)$ & $12(2.8 \%)$ & .82 \\
\hline Empyema & $20(2.5 \%)$ & $10(2.6 \%)$ & $10(2.4 \%)$ & .82 \\
\hline Renal failure & $18(2.2 \%)$ & $8(2.1 \%)$ & $10(2.4 \%)$ & .63 \\
\hline Fascial dehiscence & $14(2 \%)$ & $7(2 \%)$ & $7(2 \%)$ & 1 \\
\hline Chylothorax & $10(1.2 \%)$ & $3(0.8 \%)$ & $7(1.7 \%)$ & .35 \\
\hline Tracheoesophageal fistula & $8(1 \%)$ & $3(0.8 \%)$ & $5(1.2 \%)$ & .73 \\
\hline Intra-abdominal abscess & $7(0.9 \%)$ & $2(0.5 \%)$ & $5(1 \%)$ & .27 \\
\hline Clostridium difficile-induced colitis & $7(0.9 \%)$ & $5(1.3 \%)$ & $2(0.5 \%)$ & .13 \\
\hline Myocardial infarction & $5(0.6 \%)$ & $4(1 \%)$ & $1(0.2 \%)$ & .20 \\
\hline Reoperation for bleeding & $5(0.6 \%)$ & $1(0.3 \%)$ & $4(1 \%)$ & .38 \\
\hline Pericardial effusion & $5(0.6 \%)$ & $3(0.8 \%)$ & $2(0.5 \%)$ & .67 \\
\hline Acute hiatal hernia & $5(0.6 \%)$ & $1(0.3 \%)$ & $4(1 \%)$ & .38 \\
\hline Stroke & $4(0.5 \%)$ & $2(0.5 \%)$ & $2(0.5 \%)$ & .63 \\
\hline Alcohol withdrawal & $3(0.4 \%)$ & $2(0.5 \%)$ & $1(0.2 \%)$ & .61 \\
\hline Gastrointestinal bleeding & $3(0.4 \%)$ & $3(0.8 \%)$ & 0 & .11 \\
\hline Pancreatitis & $3(0.4 \%)$ & $2(0.5 \%)$ & $1(0.2 \%)$ & .61 \\
\hline Small bowel obstruction & $2(0.2 \%)$ & 0 & $2(0.5 \%)$ & .5 \\
\hline
\end{tabular}


the patients in the series. The median hospitalization was 10 days. All postoperative events are listed in Table 2. Overall morbidity and mortality were not statistically different between the 2 eras. The clinical factors associated with both 30 -day mortality and all cases of reintubation are listed in Table 3.

Overall, 96 (12\%) patients (27 from the early era and 69 from the later era) had evidence of aspiration postoperatively, and the incidence of pneumonia was 14\% (113 patients; 68 from the early era and 45 from the later era). Age (odds ratio, 1.05 per year; $P<.0001$ ) and later era (odds ratio, 1.90; $P=.01$ ) predicted aspiration in all patients in a multivariable model (Table 4). Postoperative aspiration was detected more commonly in the later era $(16 \%$ vs $7 \%, P<.01)$. However, even with the increased incidence of aspiration, the incidence of postoperative pneumonia was significantly decreased in the later era $(11 \%$ vs $18 \%, P<.0001)$. In particular, the incidence of pneumonia among patients who were found to aspirate was significantly lower in the later era compared with the early era $(14.5 \%$ [10 occurrences of pneumonia in the 69 patients found to aspirate in the later era] vs $44.4 \%$ [ 12 pneumonias in the 27 patients found to aspirate in the early era], $P=.003$ ). Of note, 23 of 27 episodes of aspiration in the early era were detected when patients underwent barium swallow studies for the purpose of evaluating anastomotic integrity.

TABLE 3. Clinical factors associated with reintubations and 30-day mortality by era

\begin{tabular}{|c|c|c|c|c|}
\hline & \multicolumn{2}{|c|}{ Reintubation } & \multicolumn{2}{|c|}{ 30-d Mortality } \\
\hline & $\begin{array}{c}\text { Early era } \\
(\mathbf{n}=\mathbf{2 0})\end{array}$ & $\begin{array}{c}\text { Later era } \\
(n=49)\end{array}$ & $\begin{array}{c}\text { Early era } \\
(\mathbf{n}=13)\end{array}$ & $\begin{array}{c}\text { Later era } \\
(n=15)\end{array}$ \\
\hline Pneumonia & 12 & 24 & 8 & 3 \\
\hline Pleural effusion & 1 & 5 & & \\
\hline Leak & 2 & 2 & 1 & 1 \\
\hline $\begin{array}{l}\text { Sepsis (intra-abdominal } \\
\text { process) }\end{array}$ & & 3 & 1 & 1 \\
\hline Arrhythmia/cardiac arrest & & 3 & & 4 \\
\hline Sepsis (unexplained) & 1 & 2 & & \\
\hline Hypoxia & 1 & 2 & & \\
\hline Bronchospasm & 1 & 1 & & \\
\hline Mental status changes & & 2 & & \\
\hline Liver/renal failure & 1 & & 1 & \\
\hline Congestive heart failure & 1 & & & \\
\hline Pulmonary embolus & & 1 & 1 & 1 \\
\hline $\begin{array}{l}\text { Atelectasis/mucous } \\
\text { plugging }\end{array}$ & & 1 & & \\
\hline Empyema & & 1 & & \\
\hline Ileus & & 1 & & \\
\hline Unknown & & 1 & 1 & 2 \\
\hline Tracheoesophageal fistula & & & & 1 \\
\hline Gastrointestinal bleeding & & & & 1 \\
\hline $\begin{array}{l}\text { Pancreatitis/adult } \\
\text { respiratory distress } \\
\text { syndrome }\end{array}$ & & & & 1 \\
\hline
\end{tabular}

In contrast, 58 of 69 episodes of aspiration in the later era were detected with VFSS specifically evaluating aspiration before the performance of a barium swallow. In the early era, cervical anastomosis and aspiration independently predicted pneumonia; neither anastomotic location nor aspiration predicted pneumonia in the later era (Table 4).

\section{DISCUSSION}

Despite improvements over time, esophagectomy is associated with significant morbidity and mortality, even among high-volume surgeons and centers. ${ }^{1-6,13-15}$ Respiratory complications are significant for all esophagectomy techniques and are a common cause of postoperative death. ${ }^{4,9,17,18}$ Swallowing dysfunction and silent tracheobronchial aspiration occur in a significant number of patients undergoing esophagectomy in the early postoperative period. ${ }^{21}$ The results of this study confirm that aspiration is relatively common in the early postoperative period after esophagectomy. Older age is a significant risk factor for aspiration.

Patients with tracheobronchial aspiration in any setting are significantly more likely to have pneumonia than patients with normal swallowing. ${ }^{20}$ In this study use of a comprehensive swallowing evaluation to detect aspiration before initiation of oral feedings after esophagectomy significantly reduced the incidence of pneumonia. This routine swallowing evaluation was incorporated into our postoperative care protocol after a previous review of our outcomes after esophagectomy demonstrated that postoperative pneumonia strongly predicted mortality. ${ }^{9}$ Our results are notable for a significant decrease in pneumonia despite a significant increase in the detection of aspiration after incorporation of the swallowing examination. Although this series still had a high rate of operative morbidity despite the decreased rate of pneumonia, the majority of the observed complications were able to be managed without patient mortality. Importantly, the results of this study show that a change in postesophagectomy management can significantly decrease the incidence of a major complication associated with mortality.

Aspiration after esophagectomy is associated with abnormal swallowing mechanics. ${ }^{22}$ Patients with esophageal cancer have abnormal swallowing both preoperatively, when the most significant abnormalities are in the oropharyngeal stage, and postoperatively, when the most significant deficits are in the pharyngeal phase. ${ }^{23}$ The cause of the increased incidence of aspiration between the early and later eras in this study is likely multifactorial and not only a result of routine use of very sensitive testing for aspiration. A cervical anastomosis was used much more commonly in the later era. Some episodes of aspiration that result after a cervical anastomosis likely are due to recurrent laryngeal nerve injury. However, because the incidence of recurrent nerve injury in this and other series is significantly less than the incidence of 
TABLE 4. Logistic regression model of risk factors for aspiration and pneumonia in all patients and pneumonia by era

\begin{tabular}{|c|c|c|c|c|c|c|}
\hline \multicolumn{7}{|c|}{ Aspiration and pneumonia in all patients $(n=799)$} \\
\hline \multirow[b]{2}{*}{ Variable } & \multicolumn{3}{|c|}{ Aspiration } & \multicolumn{3}{|c|}{ Pneumonia } \\
\hline & $\begin{array}{c}\text { Univariable } \\
P \text { value }\end{array}$ & $\begin{array}{c}\text { Multivariable } \\
P \text { value }\end{array}$ & OR $(95 \% \mathrm{CI})$ & $\begin{array}{c}\text { Univariable } \\
P \text { value }\end{array}$ & $\begin{array}{c}\text { Multivariable } \\
P \text { value }\end{array}$ & OR $(95 \% \mathrm{CI})$ \\
\hline Age & $<.0001$ & $<.0001$ & $1.05(1.02-1.07)$ & .21 & & \\
\hline Cervical anastomosis & $<.0001$ & .08 & $2.16(0.92-5.04)$ & .08 & .01 & $1.82(1.15-2.89)$ \\
\hline Tobacco use & .16 & .39 & $1.22(0.75-1.96)$ & .95 & & \\
\hline Induction therapy & .16 & .50 & $0.85(0.53-1.36)$ & .1 & .37 & $0.82(0.54-1.26)$ \\
\hline Thoracotomy & .0002 & .96 & $0.98(0.44-2.16)$ & .99 & & \\
\hline Later era & $<.0001$ & .01 & $1.90(1.15-3.15)$ & .004 & $<.0001$ & $0.41(0.26-0.64)$ \\
\hline Previous thoracic surgery & .54 & & & .15 & .16 & $1.51(0.85-2.69)$ \\
\hline Diabetes & .91 & & & .39 & & \\
\hline Coronary artery disease & .80 & & & .01 & .03 & $1.69(1.04-2.76)$ \\
\hline Aspiration & Not applicable & & & .01 & .007 & $2.15(1.23-3.74)$ \\
\hline
\end{tabular}

Pneumonia by era

\begin{tabular}{|c|c|c|c|c|c|c|}
\hline \multirow[b]{2}{*}{ Variable } & \multicolumn{3}{|c|}{ Early era $(n=379)$} & \multicolumn{3}{|c|}{ Later era $(n=420)$} \\
\hline & $\begin{array}{c}\text { Univariable } \\
P \text { value }\end{array}$ & $\begin{array}{c}\text { Multivariable } \\
P \text { value }\end{array}$ & OR $(95 \%$ CI $)$ & $\begin{array}{c}\text { Univariable } \\
P \text { value }\end{array}$ & $\begin{array}{c}\text { Multivariable } \\
P \text { value }\end{array}$ & OR $(95 \%$ CI $)$ \\
\hline Age & .004 & .07 & $1.02(0.99-1.05)$ & .22 & & \\
\hline Cervical anastomosis & .006 & .02 & $3.44(1.19-9.93)$ & .16 & .16 & $1.82(0.78-4.20)$ \\
\hline Tobacco use & .67 & & & .52 & & \\
\hline Induction therapy & .03 & .40 & $0.77(0.42-1.42)$ & .94 & & \\
\hline Thoracotomy & .09 & .11 & $2.44(0.82-7.19)$ & .63 & & \\
\hline Previous thoracic surgery & .008 & .08 & $2.15(0.92-5.00)$ & .93 & & \\
\hline Diabetes & .11 & .29 & $1.53(0.7-3.37)$ & .78 & & \\
\hline Coronary artery disease & .008 & .06 & $1.84(0.96-3.52)$ & .65 & & \\
\hline Aspiration & .0005 & .01 & $3.20(1.32-7.75)$ & .27 & & \\
\hline
\end{tabular}

$O R$, Odds ratio; $C I$, confidence interval.

aspiration, most aspiration episodes likely occur because of impaired swallowing mechanics. ${ }^{21-23}$ A cervical anastomosis has potential advantages over other locations, including allowing a more extensive esophageal resection, being useful for tumors throughout the length of the esophagus, and potentially avoiding the use of a thoracotomy. ${ }^{13}$ In addition, leaks in the cervical location can typically be managed conservatively more often than leaks in other locations. ${ }^{24}$ Indeed, the majority of esophageal surgeons worldwide perform cervical anastomoses. ${ }^{25}$ Our data show that incorporating a routine swallow evaluation can mitigate complications from short-term aspiration that might be associated with cervical anastomoses.

A limitation of this study is that a statistically significant difference in mortality between the 2 eras was not demonstrated despite the clinically and statistically significant decrease in pneumonia. Although this study is large compared with other published esophagectomy series, it is underpowered to detect differences in the relatively low rates of mortality in both eras. Another potentially significant limitation is that unmeasured patient care factors that could affect pneumonia rates, such as changes in intensive care unit care and extubation policies, are not considered in the analysis. Although there were no explicitly defined changes in patient care practices over the course of the study, general improvements in patient care over time might have occurred, resulting in an overestimation of the effect of the use of the swallowing evaluation. In addition, the incidence of aspiration in the early era is likely underestimated because formal sensitive testing for aspiration was not used. Other limitations include the inherent limitations associated with all retrospective studies and the fact that only patients at a single institution were examined, which potentially limits the generalizability of the results.

In conclusion, esophagectomy is a procedure associated with morbidity and mortality that has improved over time but is still considerable. Measures that avoid respiratory complications result in better outcomes. Aspiration is common in the early period after esophagectomy. A comprehensive swallowing evaluation before initiating oral feeding after esophagectomy reduces the incidence of pneumonia. We believe all patients should undergo a formal swallowing evaluation before their diet is advanced after esophagectomy.

\section{References}

1. Bailey SH, Bull DA, Harpole DH, Rentz JJ, Neumayer LA, Pappas TN, et al. Outcomes after esophagectomy: a ten-year prospective cohort. Ann Thorac Surg. 2003;75:217-22. 
2. Chang AC, Ji H, Birkmeyer NJ, Orringer MB, Birkmeyer JD. Outcomes after transhiatal and transthoracic esophagectomy for cancer. Ann Thorac Surg. 2008;85:424-9.

3. Rentz J, Bull D, Harpole D, Bailey S, Neumayer L, Pappas T, et al. Transthoracic versus transhiatal esophagectomy: a prospective study of 945 patients. $J$ Thorac Cardiovasc Surg. 2003;125:1114-20.

4. Connors RC, Reuben BC, Neumayer LA, Bull DA. Comparing outcomes after transthoracic and transhiatal esophagectomy: a 5-year prospective cohort of 17,395 patients. J Am Coll Surg. 2007;205:735-40.

5. Dimick JB, Wainess RM, Upchurch GR Jr, Iannettoni MD, Orringer MB. National trends in outcomes for esophageal resection. Ann Thorac Surg. 2005;79: 212-6.

6. Ra J, Paulson EC, Kucharczuk J, Armstrong K, Wirtalla C, RapaportKelz R, et al. Postoperative mortality after esophagectomy for cancer: development of a preoperative risk prediction model. Ann Surg Oncol. 2008;15: 1577-84.

7. Daly JM, Fry WA, Little AG, Winchester DP, McKee RF, Stewart AK, et al. Esophageal cancer: results of an American College of Surgeons Patient Care Evaluation Study. J Am Coll Surg. 2000;190:562-72.

8. Orringer MB, Marshall B, Chang AC, Lee J, Pickens A, Lau CL. Two thousand transhiatal esophagectomies: changing trends, lessons learned. Ann Surg. 2007; 246:363-72.

9. Atkins BZ, Shah AS, Hutcheson KA, Mangum JH, Pappas TN, Harpole DH Jr, et al. Reducing hospital morbidity and mortality following esophagectomy. Ann Thorac Surg. 2004;78:1170-6.

10. Wright CD, Kucharczuk JC, O'Brien SM, Grab JD, Allen MS. Predictors of major morbidity and mortality after esophagectomy for esophageal cancer: a Society of Thoracic Surgeons General Thoracic Surgery Database risk adjustment model. J Thorac Cardiovasc Surg. 2009;137:587-95.

11. Luketich JD, Alvelo-Rivera M, Buenaventura PO, Christie NA, McCaughan JS, Litle VR, et al. Minimally invasive esophagectomy: outcomes in 222 patients. Ann Surg. 2003;238:486-94.

12. de Boer AG, van Lanschot JJ, van Sandick JW, Hulscher JB, Stalmeier PF, de Haes JC, et al. Quality of life after transhiatal compared with extended transthoracic resection for adenocarcinoma of the esophagus. J Clin Oncol. 2004;22: 4202-8.
13. D'Amico TA. Surgery for esophageal cancer. Gastrointest Cancer Res. 2008;2 (suppl):S6-9.

14. Birkmeyer JD, Siewers AE, Finlayson EV, Stukel TA, Lucas FL, Batista I, et al Hospital volume and surgical mortality in the United States. N Engl J Med. 2002; 346:1128-37.

15. Birkmeyer JD, Stukel TA, Siewers AE, Goodney PP, Wennberg DE, Lucas FL. Surgeon volume and operative mortality in the United States. $N$ Engl J Med. 2003;349:2117-27.

16. Paulson EC, Ra J, Armstrong K, Wirtalla C, Spitz F, Kelz RR. Underuse of esoph agectomy as treatment for resectable esophageal cancer. Arch Surg. 2008;143. 1198-203.

17. Decker G, Coosemans W, De Leyn P, Decaluwé H, Nafteux P, Van Raemdonck D, et al. Minimally invasive esophagectomy for cancer. Eur J Cardiothorac Surg. 2009;35:13-20.

18. Hulscher JB, van Sandick JW, de Boer AG, Wijnhoven BP, Tijssen JG, Fockens P et al. Extended transthoracic resection compared with limited transhiatal resection for adenocarcinoma of the esophagus. $N$ Engl J Med. 2002;347:1662-9.

19. Whooley BP, Law S, Murthy SC, Alexandrou A, Wong J. Analysis of reduced death and complication rates after esophageal resection. Ann Surg. 2001;233:338-44.

20. Pikus L, Levine MS, Yang YX, Rubesin SE, Katzka DA, Laufer I, et al. Videofluoroscopic studies of swallowing dysfunction and the relative risk of pneumonia. AJR Am J Roentgenol. 2003;180:1613-6.

21. Leder SB, Bayar S, Sasaki CT, Salem RR. Fiberoptic endoscopic evaluation of swallowing in assessing aspiration after transhiatal esophagectomy. $J$ Am Coll Surg. 2007;205:581-5

22. Easterling CS, Bousamra M 2nd, Lang IM, Kern MK, Nitschke T, Bardan E, et al Pharyngeal dysphagia in postesophagectomy patients: correlation with deglutitive biomechanics. Ann Thorac Surg. 2000;69:989-92.

23. Martin RE, Letsos P, Taves DH, Inculet RI, Johnston H, Preiksaitis HG. Oropharyngeal dysphagia in esophageal cancer before and after transhiatal esophagectomy. Dysphagia. 2001;16:23-31.

24. Urschel JD. Esophagogastrostomy anastomotic leaks complicating esophagectomy: a review. Am J Surg. 1995;169:634-40.

25. Enestvedt CK, Perry KA, Kim C, McConnell PW, Diggs BS, Vernon A, et al Trends in the management of esophageal carcinoma based on provider volume: treatment practices of 618 esophageal surgeons. Dis Esophagus. 2010;23:136-44. 